\title{
An assessment approach of land-use to resource-based cities: a case study on land-use process of Daqing region
}

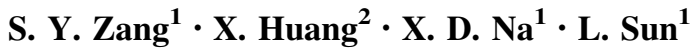

Received: 4 September 2013/Revised: 28 October 2013/Accepted: 14 March 2015/Published online: 9 April 2015

(C) Islamic Azad University (IAU) 2015

\begin{abstract}
Land is an important natural resource for national economic development, and many countries are paying more and more concerns on how to effectively utilize the resource. As an example, local petroleum industry in Daqing region is developing rapidly; it leads to the usable land resource diminishing and the agricultural ecological environment degenerating recently, such kind of land change process characterizes land-use feature of typical resource-based city. Therefore, the study of the land-use change of Daqing region is representative and instructive for most resource-based cities. To provide reasonable land use with a theoretical basis for scientific management of such resource-based region, a method to quantitatively assess and adjust the land resource use according to local economic development scenarios is introduced in the current study. Z-H model, an aggregated multivariate regression land-use dynamic model, is applied to predict the tendency of the land-use change of Daqing region in 11th Five-Year Project (11th FYP). The predicted data are compared with the planned target of regional economic development of Daqing in 11th FYP to find feasible land-use operation mode. To distinguish the features of the processes of land-use change in the resourcebased region from the others, however, some indicators (such as specific driving efficiency and specific economic
\end{abstract}

S. Y. Zang

zsy6311@163.com

1 Key Laboratory of Remote Sensing Monitoring of Geographic Environment, College of Heilongjiang Province, Harbin Normal University, No. 1 South Shida Road, Limin Economic Development Zone, Harbin, Heilongjiang 150025, People's Republic of China

2 Computer Center, Nanjing Forestry University, Nanjing 210037, People's Republic of China profitability) are defined in the studied case, which provide the assessment of local land use with intuitive criteria. And professional suggestion of adjustment index was proposed for scientific management of land use for the local management administration.

Keywords Z-H model - Land use - Resource-based city · Assessment $\cdot$ Daqing region

\section{Introduction}

Daqing region locates at Heilongjiang Province, northeast of China, the range is longitudinal $123^{\circ} 45^{\prime}-125^{\circ} 47^{\prime} \mathrm{E}$ and latitudinal $45^{\circ} 23^{\prime}-47^{\circ} 28^{\prime} \mathrm{N}$, and its area covers $2.12 \times 10^{4} \mathrm{~km}^{2}$. It is relying on the dominant industry of petroleum exploitation and petroleum product production and developing its supporting industries simultaneously and has formed a complete industry system gradually. So far Daqing oil field still has been the largest petroleum production base of China and also one of the 11 largest oil fields of which accumulative total oil production exceeds 1 billion tons in the world and has kept the stable oil production record of more than $50 \mathrm{M}$ ton year ${ }^{-1}$ for 24 years. Impacted by petroleum exploitation and petroleum product production, the land-use change/cover (LUCC) processes of Daqing region present particular characteristics and regularity of land change pattern of resource-based cities.

Due to lack of sufficient recognition on the management of land resources, Daqing region expended the cost of land resource waste and ecological environmental degeneration. For such kind of region as Daqing, which rapidly develops local economy relying natural resources consumption, its regularity of LUCC is representative. The main character exhibits that the land use is intensively impacted by the 
rapid development of petroleum industrial system, which leads the land use to sharply change within short duration. Investigating the management method of land use of Daqing region has instructive significance for sustainable development and ecological environmental protection of such developing natural resource-based cities.

As mentioned before, the dominant industry of Daqing is petroleum exploitation and petroleum chemical product production. Moreover, supported by its predominance of natural resources, Daqing is actively developing replacing industry and agricultural production simultaneously, and its industrial structure evolves from the type of monotonous resource-based production to specified comprehensive production system, which leads the local economic structure to transform from monotonous resource-based industry to multi-industry production system.

Obviously, the characteristic feature of land use of Daqing is that the land-use pattern is dominated by petroleum exploitation and oil production industry; the land used for oil field construction and relevant industry is continuously expanding prior to that for other vocations. It causes the trend of the former continuous increasing and the latter decreasing. Such evolution process leads to the problems of planless land use and sharp population expansion.

Local municipal administration has paid much concern on effective utilization of natural resource and environmental protection. Many projects on LUCC have implemented, and a lot of scenarios dealing with LUCC were investigated. However, to find relevant holistic patterns and tendencies of LUCC from these observation data, it is necessary to employ a valid model and reduce all the information into summarized and simplified forms. Since the land-use management in practice is much more complex than the data set simulated from the dynamic model, suitable and intuitive indicators have to be found to instruct the land-use management practice.

To depict the regularity of land-use change, the authors proposed an aggregated multivariate regression land-use model ( $\mathrm{Z}-\mathrm{H}$ model) to interpret the relationship between the land-use change process and its driving effect of the local economic development (Zang and Huang 2006). However, how to apply the $\mathrm{Z}-\mathrm{H}$ model to analyze the LUCC processes of a resource-based city is still a technical problem; the previous study (Zang and Huang 2006) suggested that Z-H model can be applied, respectively, to analyze the regularity of land use of each specialized zone according to different economic characteristics. And alternatively, if it is necessary, the calculated results should be summed together to predict the holistic land-use pattern and tendency of the whole region and consequently frame the land-use outline of the region. And also large sum of data observed in the survey should be summarized to define some indicators for operation in management practice.

\section{Materials and methods}

\section{Material}

Outline of natural condition and background of economic development

Daqing area locates at temperate semiarid grassland region; the natural vegetation mainly consists of meadow and small portion of salinized meadow and marsh. Recently, rapid development of petroleum industry has led to large part of the natural vegetation to be reclaimed into farmland, and quite amount of natural vegetation was seriously destroyed by the oil field construction. These data used in the current study were mainly obtained from remote sense images in different years, and the relevant information was collected from local administration and library.

\section{Pretreatment of remote sense image data of land-use change of Daqing region in the period of 1976-2005}

The raw data resource included TM image data of six time periods obtained in 1976 (September, MSS), 1986 (August and October), 1991 (April), 1996 (September), 2001 (September) and 2005 (September). The geometric boundary of the image was corrected by means of RS image processing system ERDAS 8.7 after verification and matching; then, the RS image map in different periods was made by means of direct spectrum classification. The land uses of Daqing were categorized into six types, i.e., farmland (for agricultural production), grassland, forestland, wetland (swamp, lake basin bog, floodplain, river, reservoir and pond), nonuse land (sand land, alkaline and salinized land) and built-up land (urban and rural residential land, and factory, oil field and traffic land) in order to reduce the data redundancy. The land-use data of the time period of 1981 were added to meet the need of data treatment, and the point values were obtained by specialized interpolation. The results showed that the Kappa indexes were in the highest precision of 0.7 by examining the classified results of RS images in the five periods.

Comparing with the topographic map on the scale of 1:50000 in Daqing area in 1996, TM images in 1978, 1988, 1992, 2001 and 2005 were corrected and interpreted, respectively, on the basis of the interpreted image in 1996. Landscape dynamic maps of Daqing area in 1976-1981 (Stage 1), 1981-1986 (Stage 2), 1986-1991 (Stage 3), 1991-1996 (Stage 4) and 1996-2001 (Stage 5) were obtained by overlaying the different land-use maps on 


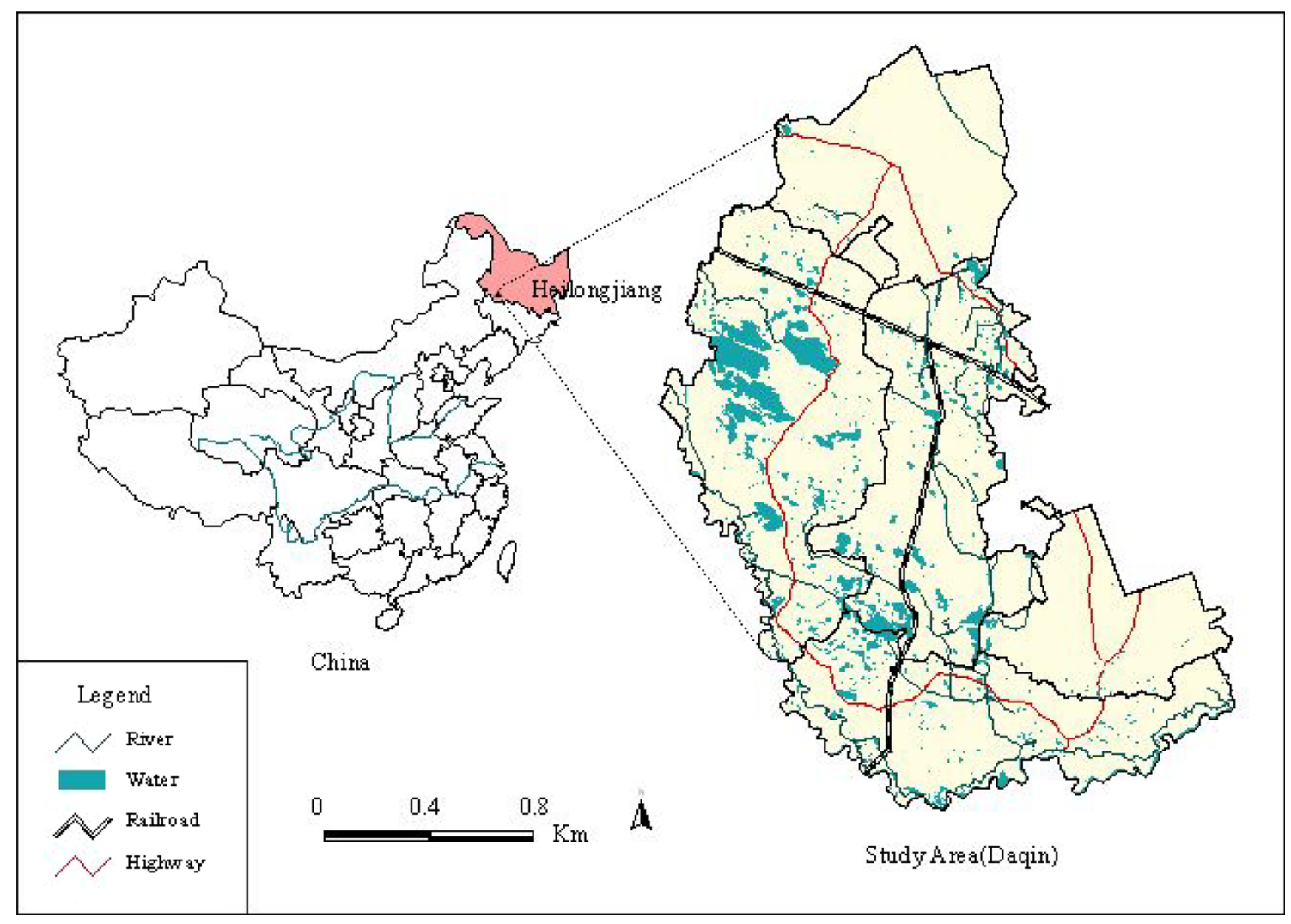

Fig. 1 Map of Daqing

ArcGIS 8.3. (Zang et al. 2005a, b). The states of every type of land use in different temporal stages were thus obtained (Fig. 1).

It was noticed that the time interval of the checked data is not unified. To be in accordance with the time checked points discussed in the context, constraint condition of land change was considered, i.e., the total area of the region was constant. The original data were linearly interpolated to divide the duration between 1980 and 2005 into five identical stages. It is not difficult to prove that the sum of all kinds of land increment equals zero and satisfies the constraint condition at each time checked point.

Considering non-balance property of local economic development, we divided Daqing region into two representative portions, urban area and suburban area (including four counties: Zhaozhou, Zhaoyuan, Lindian and Durbert) according to the application proposition of $\mathrm{Z}-\mathrm{H}$ model (Zang and Huang 2006). The time series of treated data of urban area and suburban area are illustrated in Fig. 2.

\section{Pretreatment of main economic data and social statistic} data of Daqing region in the period of 1976-2005

As a new economic zone, the social statistic data and economic data of Daqing region in different years had not been unified in the same specification, so that many kinds of data were uniformed in identical specification by derivative transformation and administration range transformation in the current study. The transformations were considered to coincide with time relation between the statistic data and the remote sense images.

Natural environment, land-use management and social/ economic factors were proposed as three main driving factors of LUCC by IGBP (International Geosphere and Biosphere Project) and IHDP (International Human Dimensions Program on Global Environmental Change) (Turner et al. 1995; Nunes and Auge 1996; Vellinge 1998). Considering the character of land-use change and driving factor of Daqing region, we categorized all the driving factors into three groups approximately, i.e., natural group, management group and economic group. In these groups, the natural factors mainly implied air temperature and precipitation; the economic group included production scale, technological progress factor and natural resources factor; and management group included scientific content of management, resident life convention. $\mathrm{Z}-\mathrm{H}$ model selected the economic group as the dominant driving force after careful study (Zang and Huang 2006).

The time series of agricultural production value (first industry production value or FIPV), industrial production 
value (second industry production value or SIPV) (unit: $10^{4} \mathrm{RMB}$ ) and population (POP) (unit: person) from 1980 to 2005 are illustrated in Fig. 3.

To stress the characteristics of the process of land-use changes in resource-based city, a rough concept, driving force density of land use, was introduced to indicate the quotient of either economic profitability or person per unit land. As the mainstay of economic structure of the urban area, the driving force density of SIPV is much higher than that of suburban, and also driving density of POP of the urban is higher than that of suburban (Fig. 4); the land use of the urban area is thus intensively influenced by such high density of driving forces. SIPV and POP, therefore, are dominative driving forces of the land-use change of the urban area. Because the SIPV is supported by the land used of petroleum exploitation, which is distributed in the whole

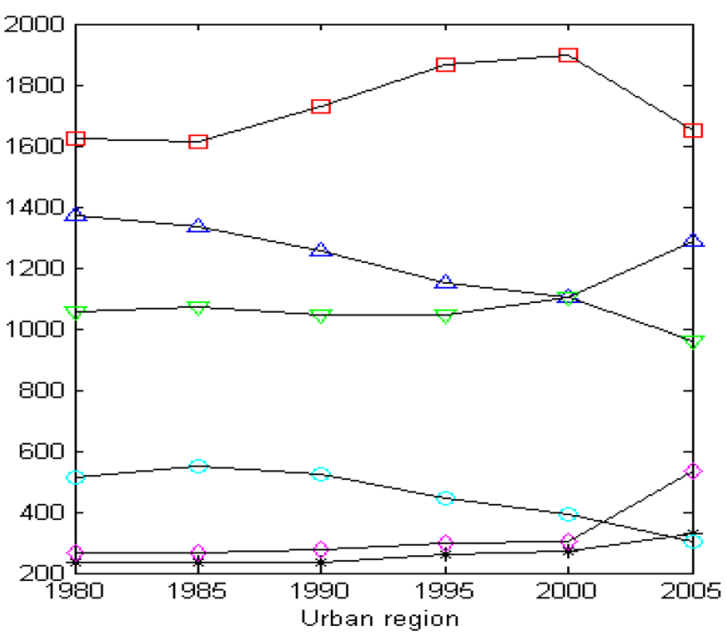

Daqing region, the industrial driving density should be the ratio of the SIPV to the whole area of Daqing region (the sum of urban area and suburban area). This is the characteristic of the land use of resource-based cities. By contrast, the economic structures of the four suburban counties mainly depend on agricultural production, although the density of driving force seems the same as that of urban, they cover large land area for agricultural production, so that FIPV is their dominant driving force, and its driving force densities of SIPV and POP are evidently lower than that of the urban area. The land-use successions are therefore categorized into two different kinds of driving types.

As Fig. 4 shows, the urban and suburban have almost the same FIPV driving force density, which implies that the density of driving force is a comparable index.

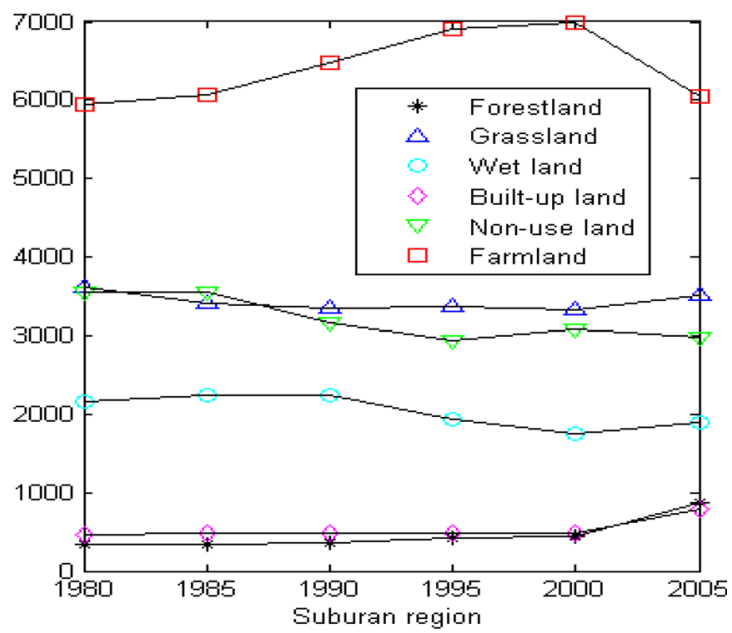

Fig. 2 Annual state of land use of Daqing region $\left(\mathrm{km}^{2}\right)$
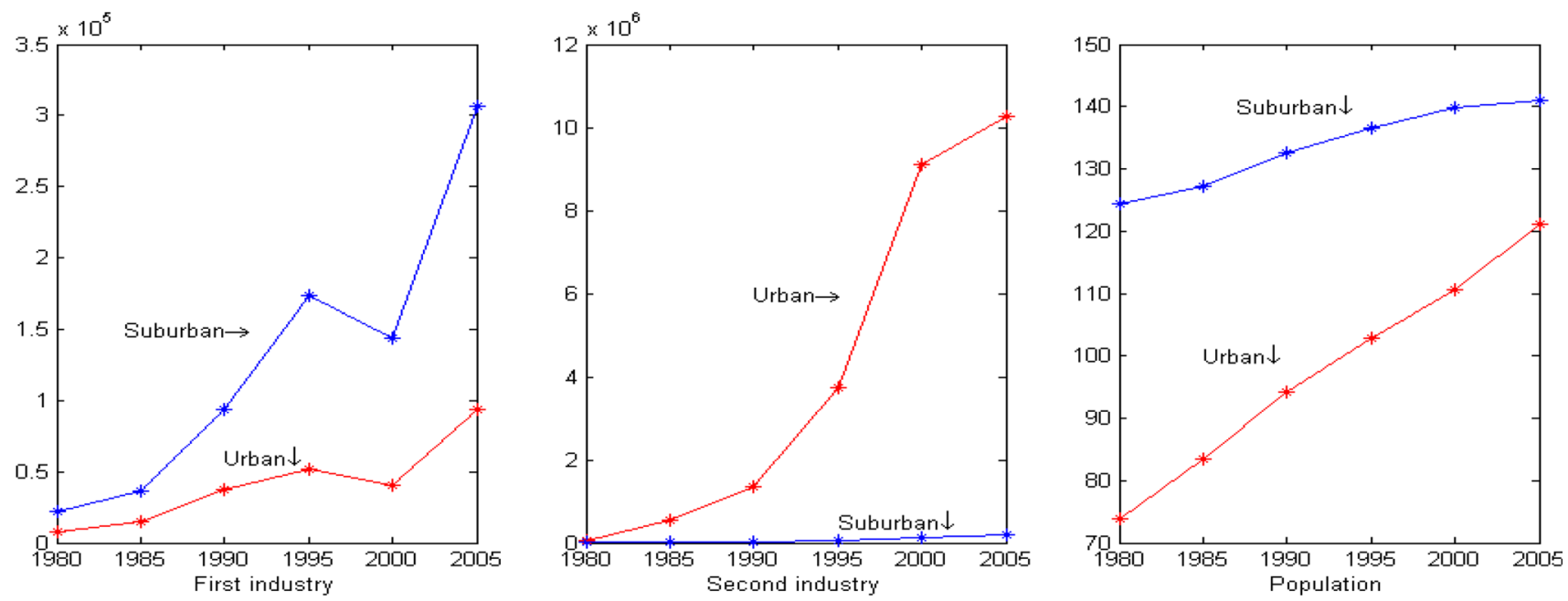

Fig. 3 Three driving forces $\left(\times 10^{-4}\right.$ RMB or person $)$ of urban area and suburban area 

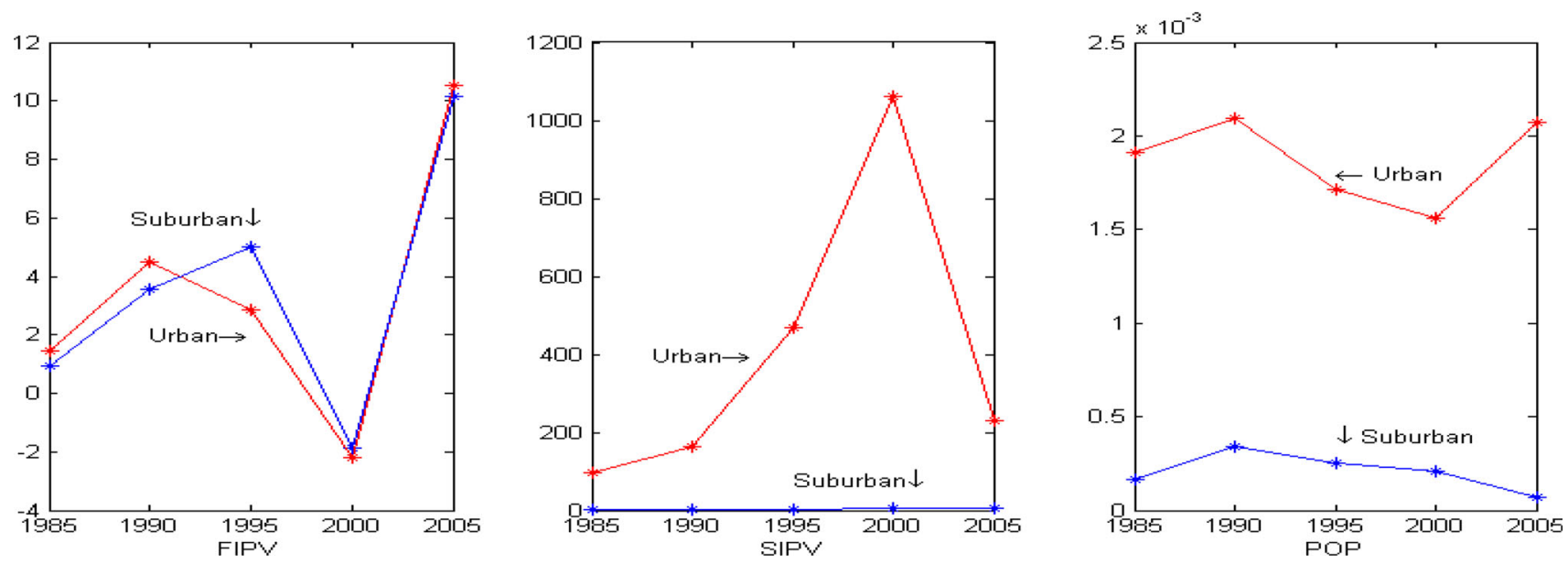

Fig. 4 Driving forces increment density

The main economic data and land-use data of Daqing region in next period (2005-2010)

In terms of 11th Five-Year Project (11th FYP) of Daqing (http://www.dqfgw.gov.cn/) and population management indexes of the National Family Plan Committee, the following data can be counted in terms of compatible price specification of 1990: The FIPV is RMB 8 billion (include 2 billion in urban area and 6 billion in suburban area); the SIPV is RMB 152 billions (include 150.2 billion in urban area and 1.8 billion in suburban area); the POP in urban area is 1.386 million (includes 0.15 million immigration from the suburban area during 11th FYP of Daqing); and the population in the suburban area is 1.438 million. Therefore, the increments of the driving force $\Delta F^{m+1}$ were counted in terms of the figure of local economic development and population control as follows (Tables 1, 2).

\section{Methods}

The dynamic model of land-use change

Like other land-use change models based on multivariate regression, Z-H model can be used to reveal the interrelation between land changes and their impacting factors within one temporal stage. But the partial coefficients in the Z-H model have their apparent physical sense, secondorder increment of land change for one-unit driving force increment, which can afford us with necessary information to analyze and explain the interrelation between land-use changes and their impacting factors. Without any abstract assumption, $\mathrm{Z}-\mathrm{H}$ model exhibits its advantages of intuitive concept and feasible operability in application.

The general form of $\mathrm{Z}-\mathrm{H}$ model is

$$
\begin{aligned}
& {\left[\begin{array}{c}
\Delta L_{1}^{m+1} \\
\Delta L_{2}^{m+1} \\
\vdots \\
\Delta L_{k}^{m+1}
\end{array}\right]=\left[\begin{array}{c}
\sum_{i=1}^{k} \Delta L_{1 i}^{m} \\
\vdots \\
\sum_{i=1}^{k} \Delta L_{k i}^{m}
\end{array}\right]} \\
& +\left[\left[\begin{array}{c}
\sum_{i=1}^{k} \frac{\partial\left(\mathrm{d} L_{1 i 1}^{m}\right)}{\partial f_{1}^{m}} \\
\vdots \\
\sum_{i=1}^{k} \frac{\partial\left(\mathrm{d} L_{k i 1}^{m}\right)}{\partial f_{1}^{m}}
\end{array}\right]\left[\begin{array}{c}
\sum_{i=1}^{k} \frac{\partial\left(\mathrm{d} L_{12}^{m}\right)}{\partial f_{2}^{m}} \\
\vdots \\
\sum_{i=1}^{k} \frac{\partial\left(\mathrm{d} L_{k i 2}^{m}\right)}{\partial f_{2}^{m}}
\end{array}\right] \cdots\left[\begin{array}{c}
\sum_{i=1}^{k} \frac{\partial\left(\mathrm{d} L_{1 i n}^{m}\right)}{\partial f_{n}^{m}} \\
\vdots \\
\sum_{i=1}^{k} \frac{\partial\left(\mathrm{d} L_{k i n}^{m}\right)}{\partial f_{n}^{m}}
\end{array}\right]\right]\left[\begin{array}{c}
\Delta f_{1}^{m} \\
\Delta f_{2}^{m} \\
\vdots \\
\Delta f_{n}^{m}
\end{array}\right]
\end{aligned}
$$

Simplified to note as: $G^{m+1}=G^{m}+H^{m} F^{m+1}$, where

$$
\begin{aligned}
G^{m+1}=\left[\begin{array}{c}
\Delta L_{1}^{m+1} \\
\Delta L_{2}^{m+1} \\
\vdots \\
\Delta L_{k}^{m+1}
\end{array}\right], \quad G^{m}=\left[\begin{array}{c}
\sum_{i=1}^{k} \Delta L_{1 i}^{m} \\
\vdots \\
\sum_{i=1}^{k} \Delta L_{k i}^{m}
\end{array}\right], \\
F^{m+1}=\left[\begin{array}{c}
\Delta f_{1}^{m} \\
\Delta f_{2}^{m} \\
\vdots \\
\Delta f_{n}^{m}
\end{array}\right]
\end{aligned}
$$

Table $1 \Delta F^{m}$ in 11th FYP of Daqing

\begin{tabular}{llll}
\hline Type & FIPV $\left(\times 10^{9} \mathrm{RMB}\right)$ & SIPV $\left(\times 10^{9} \mathrm{RMB}\right)$ & POP $\left(\times 10^{3}\right.$ person $)$ \\
\hline Urban & 1.1614 & 47.42 & 18.9 \\
Suburban & 2.931 & -0.264 & 23.6 \\
\hline
\end{tabular}


Table 2 Land pattern in 11th FYP of Daqing (unit: $\mathrm{km}^{2}$ )

\begin{tabular}{llccccc}
\hline Type & Forestland & Grassland & Wetland & Built-up land & Nonuse land & Farmland \\
\hline Urban & 291.51 & 1152.037 & 418.56 & 586.249 & 965.92 & 1652.06 \\
Suburban & 685.314 & 3436.857 & 1745.796 & 812.632 & 2935.024 & 6458.249 \\
\hline
\end{tabular}

Let $h_{\text {lip }}^{m}=\partial\left(\mathrm{d} L_{l i p}^{m}\right) / \partial f_{p}^{m}$ and $\sum_{i=1}^{k} h_{l i p}^{m}=h_{l p}^{m}$, we have

$H^{m}=\left[\left[\begin{array}{c}h_{11}^{m} \\ \vdots \\ h_{k 1}^{m}\end{array}\right] \quad\left[\begin{array}{c}h_{12}^{m} \\ \vdots \\ h_{k 2}^{m}\end{array}\right] \quad \cdots \quad\left[\begin{array}{c}h_{1 n}^{m} \\ \vdots \\ h_{k n}^{m}\end{array}\right]\right]$

where $\Delta L_{i}^{m+1}$ is the increment of land type $i$ in stage $m+1$, $\Delta L_{i j}^{m}$ is the increment of land type $i$ transferred from type $j$ in stage $m(i \in k, j \in k), \Delta f_{p}(p \in n)$ is the increment of driving force $p, h_{\text {lip }}^{m}=\partial\left(\mathrm{d} L_{\text {lip }}^{m}\right) / \partial f_{p}^{m}$ is defined as driving efficiency increment of driving force $p$ on $\Delta L_{l i}^{m}$, that is, the secondorder increment of land change for one-unit driving force increment. In the context $i \in 6, j \in 6$ and $p \in 3$.

\section{The indicators for assessment and management of land use}

$\mathrm{Z}-\mathrm{H}$ model can be used for the prediction, assessment and adjustment of regional land-use change according to different regional economic types, respectively.

\section{Prediction and assessment}

The function of formula (1) is to predict the land increment $G^{m+1}$ in stage $(m+1)$ derived from data in stage $m$.

Here, we notice a pair of variables: land increment $\Delta L_{i}^{m}$ and driving force increment $\Delta f_{p}^{m}$. The variables are both input and output each other and have apparent causal relationship. One can imagine that present economic situation (include population increment), according to its requirement, forms present land-use pattern, and the changed land-use pattern affords a new platform for the economic development in next temporal stage, that is, $\Delta f_{p}^{m}$ leads $\Delta L_{i}^{m}$ and $\Delta L_{i}^{m}$ leads $\Delta f_{j}^{m+1}$. Two indicators should, therefore, be introduced to significantly depict such relationships as: specific driving efficiency $S_{p}^{m}=\Delta L_{p}^{m} / \Delta f_{p}^{m}$ and specific economic profitability $R_{p}^{m}=\Delta f_{p}^{m+1} / \Delta L_{p}^{m}$. Their economic senses are obvious, the former is land resource increment spent for oneunit expense increment (unit for FIPV and SIPV: $\mathrm{km}^{2} / \mathrm{RMB}$, POP: $\mathrm{km}^{2} /$ person), and the latter, the economic profitability increment (include population increment) in next time stage coursed by one-unit land increment.

\section{Adjustment}

The driving forces are determined by the project of local economic development in each stage, and the land-use change pattern in the stage may be caused by this project. So that we assume that if $F^{m+1}$ and $G^{m+1}$ are known, the task of adjustment is to find adequate driving efficiency increment $H^{m}$. In fact, this is a mathematical process; from (1), we have

$H^{m}=\left(G^{m+1}-G^{m}\right)\left(F^{m}\right)^{-1}$

So each $h_{l p}^{m}$ (here noted in difference form $h_{l p}^{m}=$ $\left(\Delta L_{l p}^{m}-\Delta L_{l p}^{m-1}\right) / \Delta f_{p}^{m}$ in $H^{m}$ can be gained. In fact, $h_{l p}^{m}$ indicates the increment of specific driving efficiency of land $l$ driven by driving force $p$ in stage $m$. Keep in mind that $H^{m}$ in (1) (denoted by $H_{1}^{m}$ ) and the one suitable for new operation mode (denoted by $H_{2}^{m}$ and its elements are denoted as $\left.\tilde{h}_{l p}^{m}=\left(\Delta \tilde{L}_{l p}^{m}-\Delta L_{l p}^{m-1}\right) / \Delta f_{p}^{m}\right)$ are different, the former is derived by $\mathrm{Z}-\mathrm{H}$ model and used for prediction, and the latter is from the local economic development project and used as adjustment basis, in which $\Delta \tilde{L}_{l p}^{m}$ are calculated in terms of planned data $G^{m+1}$ and $F^{m}$ of local manage administration; thus, we have

$\Delta H^{m}=H_{2}^{m}-H_{1}^{m}$

While $F^{m}, G^{m}$ and $G^{m+1}$ are known, $\Delta H^{m}$ is the value of adjustment corresponding to feasible driving efficiency, which may afford a reference for estimating the tendency of land-use change in stage $m+1$ and guide the land-use change to avoid abandoned abuse after choosing different driving efficiency. The aim of the adjustment function, in professional term, is to revise land-use operation mode and have the land-use change met the planned land pattern.

It is obvious that $\sum_{l}^{n} \tilde{h}_{l p}^{m}$ must satisfy the constraint condition, that is $\sum_{l}^{n} \tilde{h}_{l p}^{m}=0$ (refer to "Appendix 1"); we can also check the planned data whether it is reasonable or not by means of such way.

\section{Results and discussion}

1. According to (1), we simulated the succession process of land uses during 1996-2005 and predicted the landuse increment pattern in the period of "11th Five-Year Project" (11th FYP) during 2006-2010 with the driving force $F^{m}$. Figure 5 illustrates the outcome of the simulation.

The data in Fig. 5 show that the area of farmland in both urban area and suburban counties is decreasing sharply, 

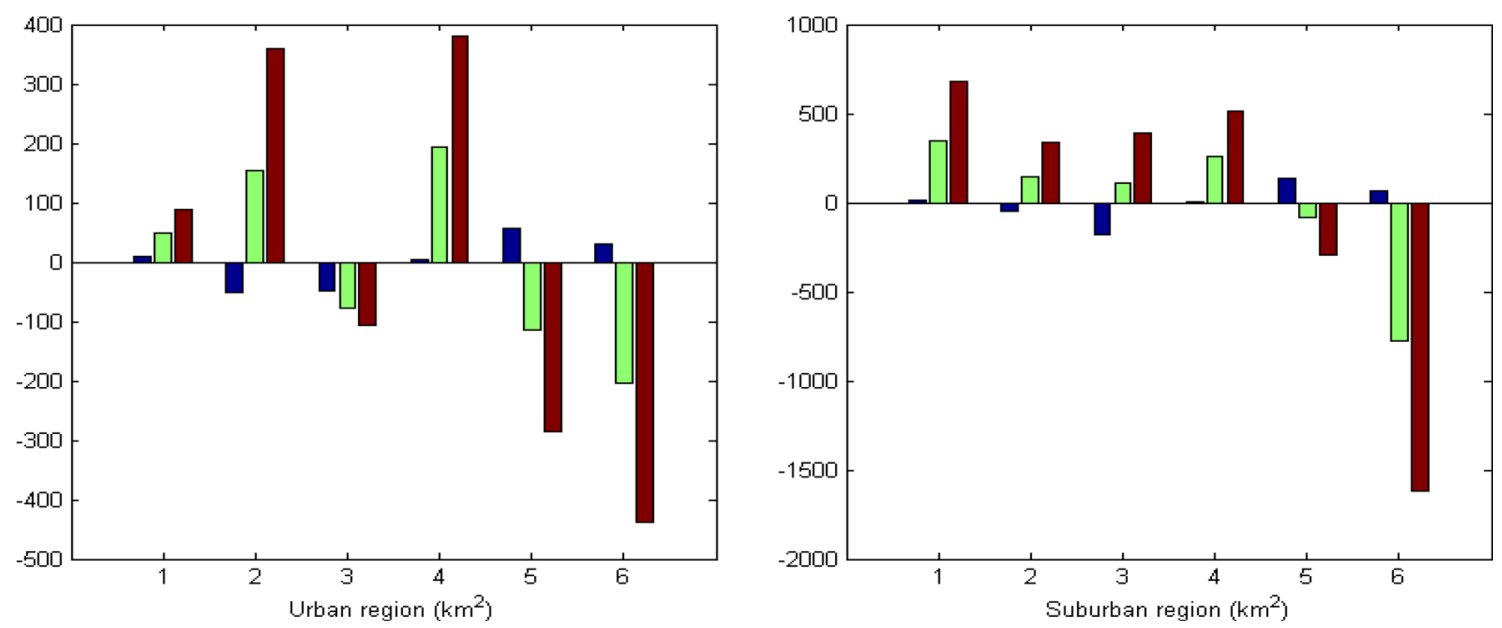

Fig. 5 Land increment at 2000, 2005 and 2010 (unit: $\mathrm{km}^{2}$ ) (1 forestland, 2 grassland, 3 wetland, 4 built-up land, 5 nonuse land, and 6 farmland)

while the forestland and grassland in urban area and suburban counties, as well as the wetland in suburban counties, are enlarged obviously since the policies of "Returning farmland back to forestland," "Returning farmland back to grassland" and "Returning farmland back to wetland" are implemented. All these also include such reasons as

a. Since the food structure of the resident is being converted from the type of staple food to the type of non-staple food, the demand of grain is decreasing while the demand of meat and aquatic products is increasing;

b. With the application of advanced agricultural technology and improvement of grain yield per unit area, the dependency on land area of agricultural production is decreasing.

If the same management mode of the land use is continuing until 2010, the decreasing of farmland and increasing of built-up land will vary intensively. This phenomenon seems to cause sufficient attention. The nonuse land and the wetland in urban area may also decrease in large magnitude; oppositely, the wetland in suburban counties will keep increasing.

The regularity of land-use change in Daqing region evidently gives prominence to the dominant function of economic structure to land pattern succession. Figure 4 illustrates that the production value density of petroleum industry (mostly concentrated in urban area while the area of gaps which are used for oil field construction and distributed in each type of land are neglected) is much higher than that of the other industries, and also, the population density of the urban area is higher than that of the suburban. The main characteristics of resourcebased city versus manufacture-based city were concluded as: a. The exploitation of mine or other natural resources consequentially destroys original land type and leads functional used lands to distribute separately, so that the land type of such areas varies quickly and intensively, and its land pattern varies rapidly, especially during the initial stage;

b. Such mining bases are always built up at rural area far from the economic developed zone; thereby, large sum of rural population are converted into urban and enterprise population with the development of the mine exploitation.

c. After adjustment of land use in each temporal stage according to local economic development project, the land-use pattern gets rid of random situation in initial period of the natural resource exploitation, and the allocation of local land use gradually becomes reasonable and stable, Figs. 6 and 7 show such fact.

2. Specific driving efficiency $S_{p}^{m}=\Delta L_{p}^{m} / \Delta f_{p}^{m}$ is counted and illustrated in Fig. 6.

Figure 6 shows that almost all specific driving efficiencies are converging to zero, which implies that the land-use increments no longer vary in large magnitude when driving factor increments increase after long-period succession. The phenomena exhibited that such land-use patterns are approaching to stable state for actual economic situation, and economic (include population) variation influences land-use change less and less, that is, the driving efficiencies are diminishing. But it should be noticed that the increment of wetland has positive divergence tendency while that of grassland has negative one with the increment of population in suburban, which imply that the two have not reached stable state.

3. Specific economic benefit $R_{p}^{m}=\Delta f_{p}^{m+1} / \Delta L_{p}^{m}$ is counted and illustrated in Fig. 7. 

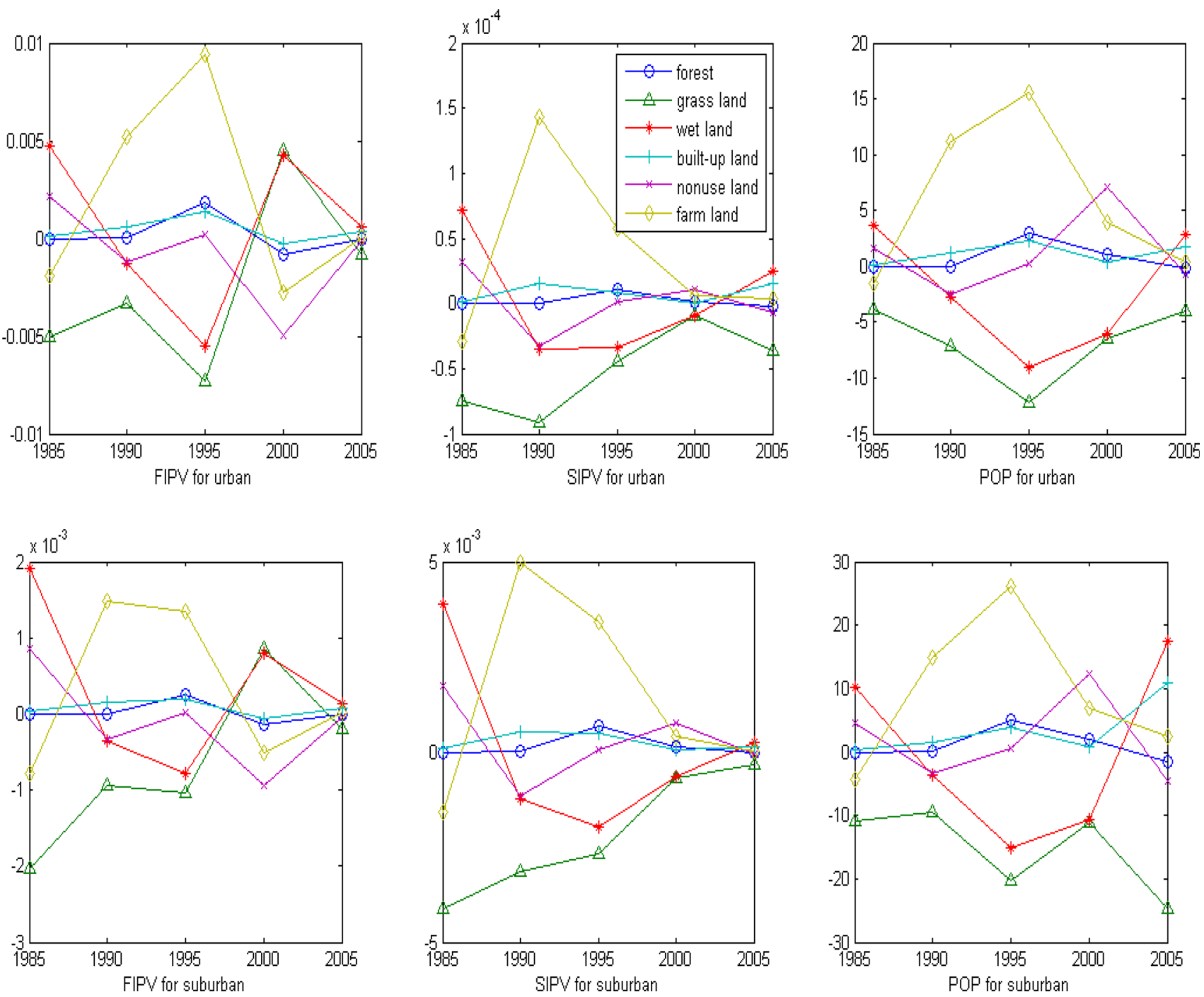

Fig. 6 Specific driving efficiency for urban and suburban (unit: $\mathrm{km}^{2} / 10^{4} \mathrm{RMB}$ or person)

Figure 7 shows that driving force increments impacted by land-use increment are concentrating within a limited interval after long-period succession; it implies that the increasing land use can no longer promote economic development intensively and approaches critical state gradually under the current economic mode.

4. According to the planed figure of economic development project (Table 1) and land-use project (Table 2) in 11th FYP of Daqing region made by the municipal government by means of gray system (private communication), the increment of the driving force $\Delta F^{m}$ and the land-use increment $G^{m+1}$ can be counted, and the revision of second-order driving efficiency increment of the urban and suburban, namely $\Delta H_{U}^{m}$ and $\Delta H_{S}^{m}$ during the 11th FYP, is obtained by means of (2) and (3) as

$$
\begin{aligned}
\Delta H_{U}^{m}= & {\left[\begin{array}{ccc}
0.0010 & 0.0000 & -60.5078 \\
-0.004 & -0.0001 & -245.9461 \\
0.0018 & 0.0000 & 109.4562 \\
-0.0025 & -0.0001 & -152.7365 \\
0.0023 & 0.0001 & 139.7466 \\
0.0034 & 0.0001 & 209.9836
\end{array}\right] \times 10^{-4}, } \\
\Delta H_{S}^{m}= & {\left[\begin{array}{ccc}
-0.0003 & -0.0298 & -33.3742 \\
-0.0001 & -0.0140 & -15.6380 \\
-0.0002 & 0.0191 & -21.3551 \\
-0.0002 & 0.0168 & -18.8252 \\
0.0001 & -0.0090 & 10.0711 \\
0.0006 & -0.0707 & 79.1214
\end{array}\right] \times 10^{-4} }
\end{aligned}
$$



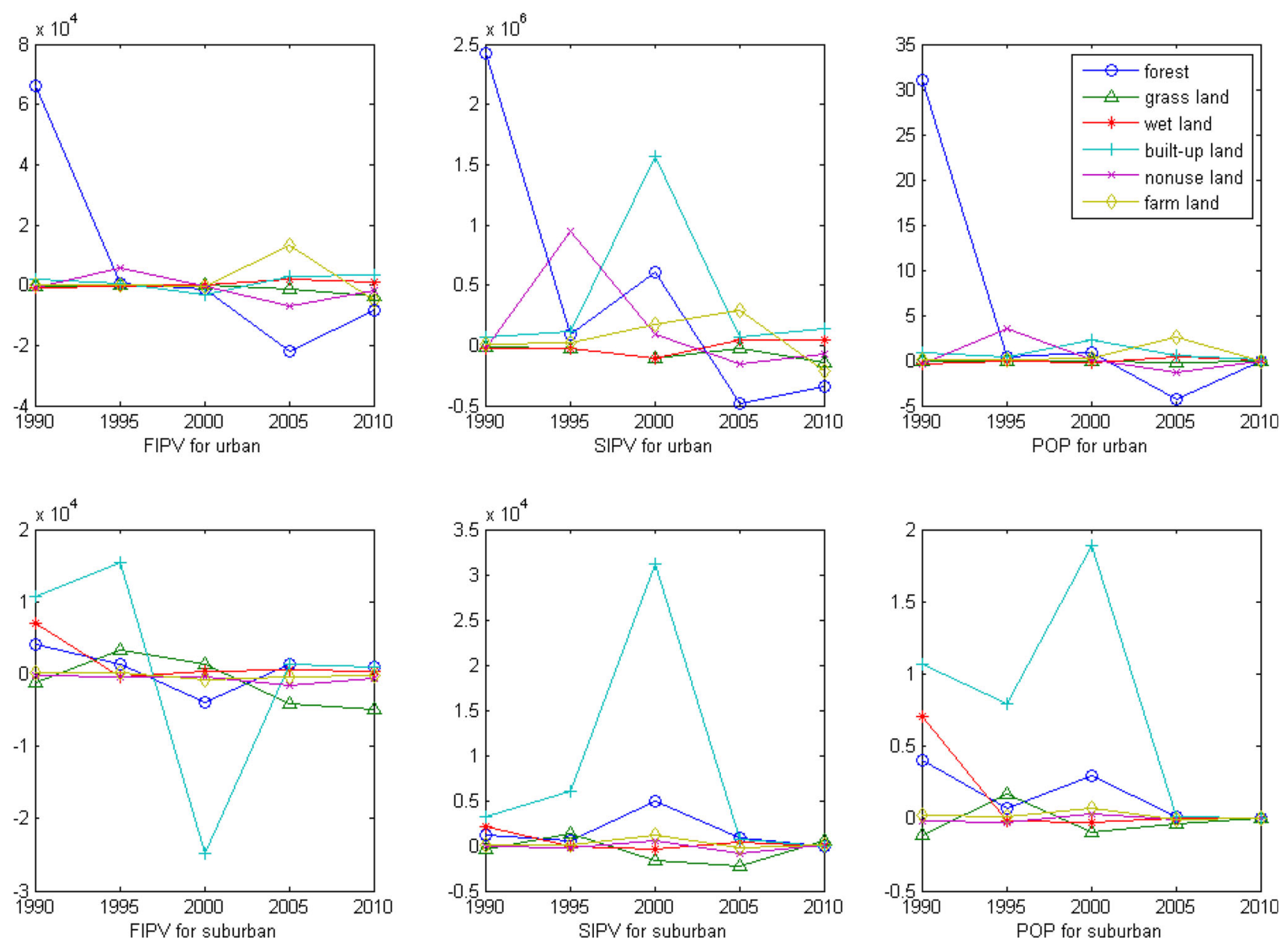

Fig. 7 Specific economic benefit for urban and suburban $\left(10^{4} \mathrm{RMB}\right.$ or person $\left./ \mathrm{km}^{2}\right)$

where for each element $h_{l m}^{p}$ in $\Delta H_{U}^{m}$ and $\Delta H_{S}^{m}$, the unit of the first and second columns $(p=1,2)$ is $\mathrm{km}^{2} \mathrm{RMB}^{-1}$, which are revision indices of second-order driving efficiency increment of FIPV and SIPV, respectively, and that in the third column is $\mathrm{km}^{2}$ person ${ }^{-1}$, which implies the revision indices of second-order driving efficiency increment of POP for each element. The sign of each element indicates the trend of the land variation under the impact of designated driving force. Addressing previous operation mode, the positive one means enhancing and the negative one means inhibiting. The row suffix $l(l \in 6)$ of $h_{l m}^{p}$ in both matrixes in turn indicates the driven land types: 1 , forestland; 2 , grassland; 3 , wetland; 4 , built-up land; 5, nonuse land; and 6 , farmland. The predicted land-use increment pattern in 2010 in Fig. 5 was produced in terms of present second-order driving efficiency increment $H^{m}$, which is derived from land-use change patterns in previous temporal stages. However, to realize the planned pattern in Table 2 during the 11th FYP, the second-order driving efficiency increments in $\Delta H_{U}^{m}$ and $\Delta H_{S}^{m}$ should be revised. The revised values may afford us criteria for how to assess the relationship between land-use increments and each type driving force.

5. Some land patches were polluted or destroyed by oil field construction and petroleum exploitation, immingled in natural vegetation or farmland in the forms of gap, which could not be distinguished in the remote sense imagine. Therefore, such part of land has not been counted in statistic data and is not discussed in context.

6. Since floating population cannot be estimated accurately, it was presumed that the immigration and emigration would approximately retain balance during the 11th FYP of Daqing.

7. $\mathrm{Z}-\mathrm{H}$ model is a quadric difference equation; its function is to predict land-use pattern in next temporal stage in terms of land-use states and attribution of driving forces in last two stages. It has been noticed that the effect of casual emergencies, such as economic policy or land-use policy change and natural disaster destruction, has not been 
considered as its mathematical regularity has not been sufficiently studied.

Therefore, the function of adjustment introduced above, considering actual local land-use states and unanticipated cases, is necessary as an auxiliary analysis approach, which may afford us criteria to estimate the next possible land-use pattern and adopt feasible operation mode.

\section{Conclusion}

Z-H model, an aggregated multivariate regression land-use dynamic model, is applied to predict the tendency of the land-use change of Daqing region in 11th FYP. The area of farmland in both urban area and suburban counties is decreasing sharply, and the forestland and grassland of both urban area and suburban counties, as well as the wetland of suburban counties, are also decreasing. The predicted data are compared with the planned target of regional economic development of Daqing in 11th FYP to find feasible landuse operation mode. The production value density of petroleum industry is much higher than that of the other industries, and also, the population density of the urban area is higher than that of the suburban. Professional suggestion of adjustment index is proposed for scientific management of land use for the local management administration.

Acknowledgments This project was financially supported by the Key National Natural Science Foundation of China (Grant No.
41030743), and the Science and Technology Innovative Programs Foundation of Higher Education of Heilongjiang Province (No. 2010td10).

\section{Appendix 1}

Because total area of any region is a constant; thereby, we have $\sum_{i=1}^{n} \Delta L_{i}^{m}=0$. As same reason, we have $\sum_{i=1}^{n} \Delta \tilde{L}_{i}^{m}=0$.

\section{References}

Nunes C, Auge JI (1996) Land use and land cover change (LUCC) implementation strategy, IGBP Report No. 48 and IHDP Report No. 10

Turner BL, David S, Liu Y (1995) Land use and land cover change science/research plan, IHDP Report No. 07

Vellinge P (1998) IHDP Industrial Transformation, IHDP-IT Publication No. 12.5

Zang SY, Huang X (2006) An aggregated multivariate regression land-use model and its application to land use change processes in the Daqing region (Northeast China). Ecol Model 193:503-516

Zang SY, Huang X, Zheng SF (2005a) Landscape processing response analysis on landuse development trend of natural resources based city - a case study in the city of Daqing. Acta Ecol Sin 27(7):1640-1648 (in Chinese)

Zang SY, Zhang J, Jia L (2005b) The landscape dynamic trend and its effect on the environment Case of Daqing City. Prog Nat Sci 15(2):321-328 